\title{
Nietzsche como crítico de la sociedad moderna'
}

José Manuel Romero Cuevas Universidad de Alcalá, Madrid, España

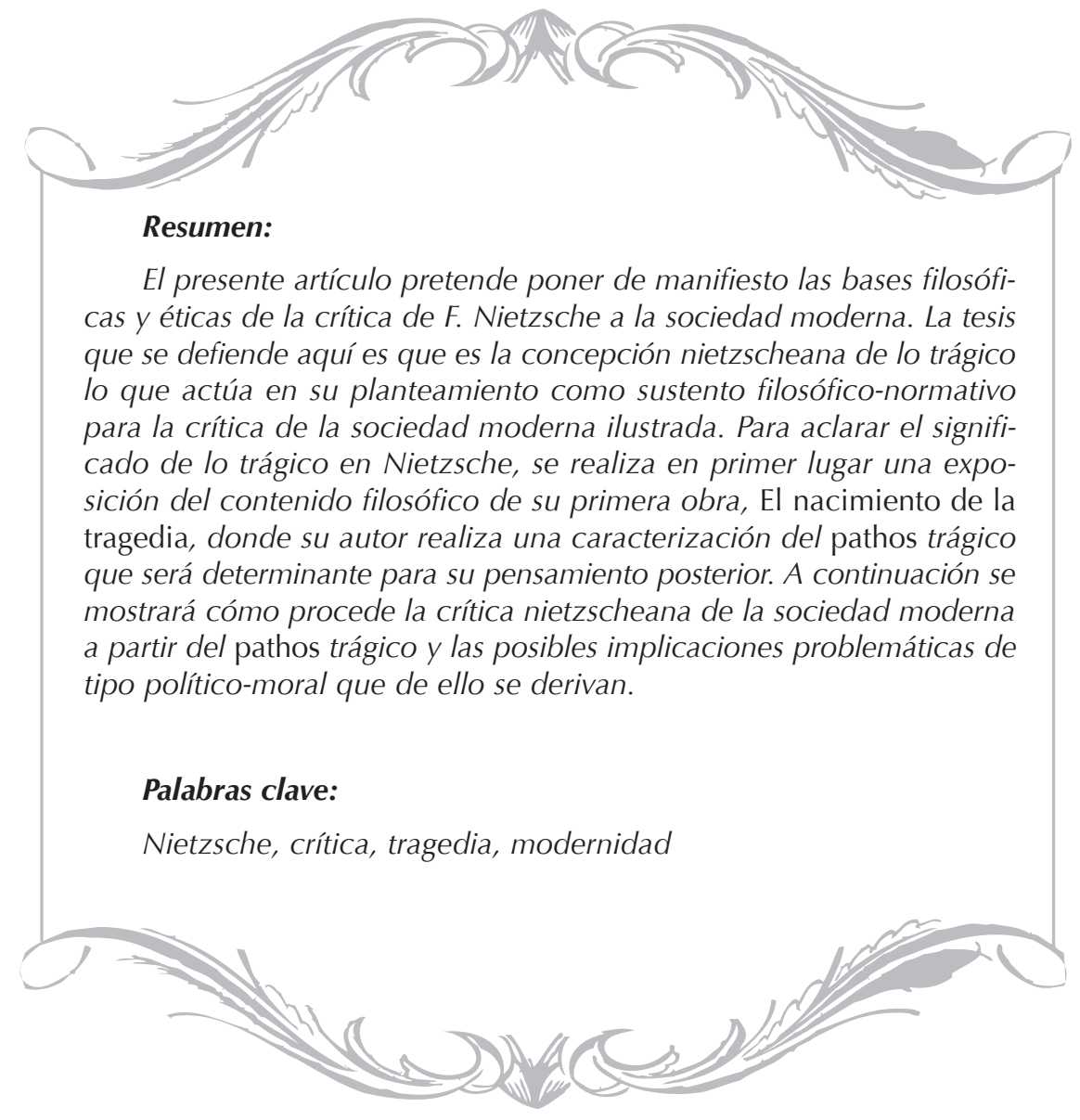


Nietzsche puede ser considerado como un pensador radicalmente intempestivo, es decir, como alguien que concibió su producción intelectual como una intervención contra su tiempo, con la intención de trascenderlo y actuar así "en favor (...) de un tiempo futuro". ${ }^{2}$ Esta pretensión intempestiva es claramente tematizable en su primera obra, El nacimiento de la tragedia, en la que la investigación históricofilosófica sobre el surgimiento de la tragedia ática en la Grecia antigua persigue efectuar una contraposición entre una forma de cultura trágica que alcanzó adecuada realización en un momento determinado del pasado y nuestro presente, marcado por el olvido y negación de lo trágico en todas sus dimensiones (artísticas, culturales, vitales y políticas). Lo trágico aparece en esta obra como la base para una confrontación crítica con el presente, un presente caracterizado en términos de modernidad, Ilustración, racionalidad y progreso. ${ }^{3}$ Pretendemos explicitar en este trabajo el modo en que la concepción nietzscheana de lo trágico actúa en su planteamiento como base normativa para una crítica de la sociedad moderna, para confron-

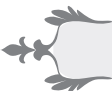

Voy a comenzar aludiendo al contenido de los parágrafos finales de El nacimiento de la tragedia, ${ }^{4}$ pues en ellos se sintetizan algunas de las tesis centrales tarnos a continuación con las posibles implicaciones problemáticas de tal crítica del presente desde la perspectiva de lo trágico. Para ello, y para contextualizar el lugar que ocupa en el pensamiento del primer Nietzsche el concepto de lo trágico - fundamental en su pensamiento desde un punto de vista filosófico, ético y político-, vamos a comenzar exponiendo las tesis principales de El nacimiento de la tragedia, tal como son sintetizadas en los dos últimos parágrafos del libro (los parágrafos 24 y 25), que constituyen una especie de balance de la obra (I). A continuación, explicitaremos el significado de lo trágico en esta obra a partir de un breve contraste con el pensamiento de Schopenhauer (II). Finalmente, mostraremos cómo procede la crítica de Nietzsche a la sociedad moderna a partir del significado atribuido por él al pathos trágico; vamos a rastrear el modo en que tal modo de crítica constituye el nervio de la oposición del Nietzsche maduro a la sociedad moderna, que según Nietzsche pretendería haber plasmado la moral judeo-cristiana, y determinaremos sus posibles implicaciones problemáticas desde un punto de vista ético-político (III).

del libro, que nos van a permitir contextualizar filosóficamente la concepción de lo trágico del primer Nietzsche, base de su crítica de la sociedad moderna 
tanto en esta obra como en sus obras finales. En los parágrafos de $E I$ nacimiento de la tragedia que aquí nos ocupan, Nietzsche realiza una especie de balance del conjunto del libro respecto a los siguientes temas:

i) Se sostiene la tesis de que en la tragedia griega (pero también hemos de suponer que en la obra de arte total wagneriana, pues en ella se efectuaría un auténtico renacimiento de la tragedia) se realiza la "alianza fraternal de Apolo y Dionisio", es decir, ella representa "la cúspide tanto de los propósitos artísticos apolíneos como de los dionisíacos" (\$24, 185). La tragedia implica pues una síntesis de ambos principios artísticos, aunque para Nietzsche lo dionisíaco posee primacía ontológica y estética sobre lo apolíneo, en cuanto que "lo dionisíaco, comparado con lo apolíneo, se muestra como el poder artístico eterno y originario que hace existir el mundo entero de la apariencia" $(\S 25,190)$. A pesar de que al comienzo del libro Nietzsche sostuvo que lo apolíneo y lo dionisíaco son "instintos artísticos de la naturaleza" $(\S 2,47)$, ahora parece sostener que lo dionisíaco corresponde a la esencia misma de la realidad como natura-naturans o Uno primordial, como sujeto artístico que crea el mundo de la individuación como juego y obra de arte, sirviéndose para ello de lo apolíneo, para destruirlo con fruición después. ii) En concordancia con ello, se caracteriza al artista trágico por su placer por la apariencia (en la que hay que incluir el ámbito de la individuación), pero al mismo tiempo por su aún más placentera destrucción de tal individuación aparente $(\S 24,186)$. El artista trágico reproduce en su praxis artística el modo de acontecer de la natura-naturans y actúa, al mismo tiempo, como un medium de lo Uno primordial, a través del cual este alcanza una más alta y plena redención de su sufrimiento originario en la obra de arte trágica.

iii) El arte es concebido como un "suplemento metafísico" de la realidad (\$24, 187), como una transfiguración de la realidad. Ahora bien, no transfigura su carácter de realidad, sino que su transfiguración consiste en la afirmación y justificación de la realidad tal como es, incluso en sus aspectos terribles. Por ello sostiene Nietzsche que tanto la música como el mito trágico "juegan con la espina del displacer (...); ambos justifican con ese juego incluso la existencia de «el peor de los mundos»" (\$25, 190). El arte trágico es, en consecuencia, un arte afirmador y justificador de la inmanencia, a pesar de sus aspectos terribles. ${ }^{5}$

iv) Esta concepción del arte se sustenta en lo que el mismo Nietzsche denomina "metafísica de artista", que ya hemos esbozado más arriba, según la cual el mundo 
en su integridad, incluyendo "lo feo y lo disarmónico, son un juego artístico que la voluntad" (o lo Uno primordial), "juega consigo misma, en la eterna plenitud de su placer" $(\S 24,188)$. El arte humano recibe en el primer Nietzsche como modelo la praxis artística en la que consiste el ser originario de la naturaleza en cuanto que natura-naturans, como divinidad que se comporta con el mundo fenoménico como lo hace un artista con su material. ${ }^{6}$

v) De aquí se deriva una relevante tesis de El nacimiento de la tragedia, a saber, que "solo como fenómeno estético aparecen justificados la existencia y el mundo" (§24, 187-188, ver también §5, 66). Estamos ante una forma de cosmodicea, es decir, de una justificación del mundo a pesar del mal presente e inherente a él. Lo propio de esta cosmodicea es que no se lleva a cabo con medios morales, sino estéticos: el mundo está justificado no en cuanto posee un determinado estatuto moral, sino en cuanto que posee un carácter artístico. Estamos, pues, ante una cosmodicea esteticista que solo puede llevarse a cabo a partir de la otorgación del estatuto de obra de arte a la totalidad de la realidad, gracias a la postulación de una divinidad que parece coincidir con el fondo originario de la naturaleza, la natura-naturans, que se plasma como natura-naturata a través de una praxis de configuración de formas delimitadas (apolíneas) y de placentera destrucción (dionisíaca) de las mismas, creación-destrucción que para Nietzsche da el prototipo de la praxis artística.

vi) Estos parágrafos finales reafirman una antítesis central para la argumentación de la obra, a saber, la antítesis entre, por un lado, civilización/llustración (latina y francesa) y, por otro, cultura (griega y alemana). La civilización/llustración es caracterizada en estas páginas como un proceso de racionalización, secularización y desmitificación que desublima los fundamentos míticos y las fuentes originarias de la cultura, sobre todo su substrato dionisíaco. Según Nietzsche, la civilización/ Ilustración:

a) Debilita el mito, y su efecto fundamental es "el carácter abstracto de nuestra existencia sin mitos" $(\S 24,189)$. Para el primer Nietzsche, el individuo solo puede vivir con sentido en el marco de un horizonte de mitos que dan consistencia a su ser. En ausencia de tal horizonte, el individuo se ve sometido a los vaivenes de la moda, a la mercantilización y a la sobreinformación fomentada por la esfera pública burguesa. Con ello pierde sus raíces fundantes en la cultura propia y se convierte en un sujeto estandarizado, convencional y amoldable a los imperativos provenientes de la economía y la política modernas.

b) Devalúa el arte a "mero deleite", al desconectar al arte dionisíaco (la música) de sus fuentes 
originarias. El arte pierde su carácter metafísico para devenir simple objeto de distracción o, aún peor, motivo de distinción social, pero sin que sirva a los fines de configuración de una cultura trágica.

c) Define una forma de vida guiada por el concepto, es decir, por la ratio, en la que se anudan la racionalidad lógica abstracta y la búsqueda del estrecho interés individual. La ratio se caracterizaría por colocar tales fines prácticos egoístas por encima de la creación de una cultura elevada en la que alcance redención y justificación lo Unoprimordial.

d) Está impulsada por el "optimismo socrático", que es un principio ajeno al arte y corrosivo de la vida (§24, 189), pues piensa que a través de la razón cabe un conocimiento y una transformación de la esencia de la vida. Con ello haría perder su privilegio metafísico al arte dionisíaco y desublimaría el fondo originario terrible que confiere su carácter trágico a la vida. ${ }^{7}$

En contraposición a ello se encuentra el espíritu alemán (o el "ser alemán"), el cual posee una profundidad y una fuerza dionisíacas no destruidas y aún "continúa soñando

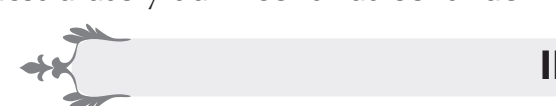

De entre los diversos temas apuntados, voy a centrarme en uno que considero central en esta su ancestral mito dionisíaco", pues no ha perdido su "patria mítica", a saber, lo griego-dionisíaco. Efectivamente, para Nietzsche el espíritu alemán está aún subterráneamente comunicado con lo griego-dionisíaco originario. Por último, Nietzsche espera que este espíritu alemán despierte algún día $(\$ 24,189)$ y cree que jugará un papel fundamental en ello el renacimiento de la tragedia plasmado en la obra de Wagner.

vii) La "música dionisíaca" (y como tal hay que calificar a la música de Wagner) nos devuelve el mito trágico, del cual cabe esperar algo de máxima importancia nacional para la Alemania recién unificada en forma de Reich: que el genio alemán salga de la prolongada indignidad en que ha vivido "extrañado de su casa y de su patria, al servicio de pérfidos enanos", es decir, dominada y colonizada por la civilización/llustración francesa $(\$ 24,189)$ y logre forjarse una cultura propia en la que se plasme y exteriorice adecuadamente su ser propio. La liberación del espíritu alemán en el plano artístico-cultural impulsada por Wagner debe acompañar a la victoria bélica sobre la civilización francesa efectuada en el campo de batalla. ${ }^{8}$ 
pathos trágico. Lo que me propongo aquí es mostrar en qué medida el pathos trágico sirve de sustento a la crítica nietzscheana del presente.

Para clarificar el significado del pathos trágico en El nacimiento de la tragedia, lo mejor es quizá analizar aquello que se le contrapone del modo más radical, a saber, lo socrático y la consideración teórica del mundo $(\$ 17,140)$. De lo socrático me interesa aquí sobre todo su caracterización por parte de Nietzsche como un impulso, plasmado en la ciencia, de conocer y transformar la realidad, guiado por la idea de que no existe ninguna esencia o núcleo profundo de la realidad capaz de resistirse a tal ímpetu de conocimiento y de transformación: Nietzsche se refiere a "una profunda representación ilusoria, que por vez primera vino al mundo en la persona de Sócrates, - aquella inconcusa creencia de que, siguiendo el hilo de la causalidad, el pensar llega hasta los abismos más profundos del ser, y que el pensar es capaz no solo de conocer, sino incluso de corregir el ser. Esta sublime ilusión metafísica le ha sido añadida como instinto a la ciencia" $(\$ 15,127)$. Efectivamente, esta forma de optimismo teórico se plasma de manera ejemplar en Sócrates, el cual "creyó tener que corregir la existencia" $(\$ 13,116-117)$.

Ahora bien, ¿a qué se opone propiamente el optimismo? $\mathrm{Na}$ turalmente al pesimismo, y a este lo vamos a caracterizar a partir de la tesis de que el mal es inherente al mundo, es decir, está arraigado en su esencia misma y es por ello inextricable de él. Esta tesis se la podemos atribuir, es patente, a Schopenhauer, pero no solo a él. También la "sabiduría dionisíaca" $(\S 22,174)$, el "conocimiento dionisíaco" $(\$ 16,136)$ y la correspondiente "verdad dionisíaca" (\$10, 98), la cual es sin lugar a dudas una "horrenda verdad" $(\S 7,78)$, apuntan a tal concepción del mundo: "El hombre dionisíaco se parece a Hamlet: ambos han visto una vez verdaderamente la esencia de las cosas, ambos han conocido, y sienten náusea de obrar; puesto que su acción no puede modificar en nada la esencia eterna de las cosas" ( $§ 7$, 78). Al acceder a la horrenda verdad, el hombre dionisíaco "ve en todas partes únicamente lo espantoso o absurdo del ser (...) ahora reconoce la sabiduría de Sileno, dios de los bosques: siente náuseas" (Ibíd. Ver también §3, 52). Podríamos sintetizar la sabiduría dionisíaca en la constatación de que el sentido de la existencia de los individuos se agota en estar condenados a desaparecer y reintegrarse en cuanto meras apariencias en el gran río del ser que es la vida originaria, en lo Uno primordial que constituye el corazón del mundo. Para los individuos no cabe ninguna esperanza ni expectativa de trascendencia alguna. $\mathrm{Ni}$ siquiera les corresponde un estatuto ontológico digno: son meras apariencias que lo Uno primordial o la volun- 
tad (es decir, lo que propiamente es) crea y destruye como un mero juego (\$24, 188). Somos, con todo nuestro sufrimiento y todos nuestros anhelos, un juguete de una divinidad amoral que juega a crear y destruir mundos más allá del bien y del mal, tal como Nietzsche sostiene en su "Ensayo de autocrítica" (31). Esta visión de la vida, espeluznante para el individuo, converge así con una visión pesimista del mundo: el mal (para el individuo) arraiga en la esencia del mundo y es inextricable del mismo.

Pero la sabiduría dionisíaca no es meramente un pesimismo sin más. Es aquí donde se juega la especificidad del planteamiento del primer Nietzsche respecto de Schopenhauer. Recordemos que para este el pesimismo consiste en la concepción de que el mal presente en el mundo está originado en su propia esencia, en la voluntad, que determina la lucha de todos contra todos en los diversos planos en los que se objetiva esta, hasta llegar a los seres humanos. Lo significativo aquí es que Schopenhauer derivaba de este pesimismo la necesidad de una negación de la causa del mal, en este caso, una negación de la voluntad, que se plasmó en su prescripción de una actitud análoga a la del nirvana como liberadora de la guerra universal que desgarra a la propia esencia del mundo. ${ }^{9}$

Pues bien, si para Schopenhauer el individuo viviría la ani- quilación del principio de individuación con un "enorme espanto", en tanto que lo abre a una verdad terrible para él, en la experiencia dionisíaca tal como la concibe Nietzsche ese espanto convive con un "éxtasis delicioso que, cuando se produce esa misma infracción del principium individuationis, asciende desde el fondo más íntimo del ser humano, y aun de la misma naturaleza" $(\S 1,43)$. A lo dionisíaco es inherente ambas respuestas ante la constatación del supremo mal para los individuos (su ausencia de consistencia ontológica, su estatuto de medios artísticos de lo Uno primordial, la ausencia de esperanza y salvación trascendentes para ellos): el placer en el espanto, es decir, la afirmación jubilosa de lo terrible. Lo dionisíaco está caracterizado por un placer primordial ante "la construcción y destrucción por juego del mundo individual", por un placer sentido "incluso en el dolor" $(\S 24,188)$.

Desde mi punto de vista, lo dionisíaco así definido da la clave para lo que el primer Nietzsche entiende por pathos trágico. Este se pone en juego explícitamente como contrapuesto a la forma de pesimismo schopenhaueriano, que de la constatación de la inherencia del mal al mundo deriva la necesidad moral de una negación de este. Lo propio de lo trágico es para Nietzsche, en cambio, su pathos afirmativo, es decir, la afirmación de la existencia y del mundo a 
pesar del mal inherente a ellos (y en consecuencia inextricable de los mismos). Esta actitud de afirmación de lo terrible es apuntada por Nietzsche en su "Ensayo de autocrítica". Ahí se pregunta: "¿Existe un pesimismo de la fortaleza? ¿Una predilección intelectual por las cosas duras, horrendas, malvadas, problemáticas de la existencia, predilección nacida del bienestar, de una salud desbordante, de una plenitud de la existencia?" (26). Lo trágico puede caracterizarse por tanto como un pesimismo de la fortaleza que aun constatando que el mal (mejor dicho, lo que la moral imperante califica de mal) es inherente al mundo, afirma y justifica este a partir de una posición ante la realidad caracteriza-

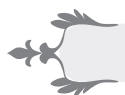

Esta concepción de lo trágico como pathos afirmativo sirve en Nietzsche de punto de apoyo para un cuestionamiento de la cultura dominante en occidente, que alcanza su manifestación más completa en la modernidad, lo que en su primera obra es denominada como cultura socrática o alejandrina. Esta cultura aparece a la luz del pathos trágico como ilusamente optimista, en cuanto que pretende que a través de la ciencia y la técnica cabe un conocimiento y una transformación en profundidad de la realidad. Esta cultura optimista pretendería efectuar una reducción del mal y del sufrimiento general a partir de los conocimientos científicos y de da por la salud y la plenitud, por la superioridad y la fortaleza. El pathos trágico, pues, está solo al alcance de los fuertes, de aquellos que se han distanciado de la visión moral del mundo dominante en occidente, es decir, la visión judeo-cristiana, y que afrontan la existencia con una actitud más allá del bien y del mal, que concibe la perfección en términos estéticos y en términos de poder, pero no en términos morales (judeocristianos). El individuo que hace gala del pathos trágico es lo suficientemente fuerte como para afirmar $y$ querer la vida tal como es, con toda su carga de sufrimiento e injusticia, y quererla así para sí mismo, sin que esto último provoque sombra alguna en su querer.

III

los medios técnicos disponibles, pretendería que el saber y la formación son accesibles a todos por igual en tanto que seres racionales y prometería un bienestar material en aumento. Pues bien, a partir de su tesis de que el mal es inherente e inextricable del mundo y de la vida y de que ello no supone ningún obstáculo para la afirmación y justificación del mundo y de la vida tal como son frente a todo menospreciador de los mismos, la cultura socrático-alejandrina recibe una iluminación precisa: como impulsada por una ilusión de nefastas consecuencias. Nietzsche es capaz de poner de manifiesto una auténtica dialéctica de la llustración ${ }^{10}$ 
(también se podría hablar de una tragedia de la llustración), por la que el seguimiento de la sociedad ilustrada de sus principios y metas propias desemboca en una autodesfundamentación de las bases mismas de la estructura social que pone en peligro la supervivencia de la sociedad en cuanto tal. Vamos a leer con detenimiento el pasaje de El nacimiento de la tragedia donde se expone esta peculiar dialéctica de la llustración:

¡Y ahora debemos no ocultarnos lo que se esconde en el seno de esa cultura socrática! ¡Un optimismo que se imagina no tener barreras! ;Ahora debemos no asustarnos si los frutos de ese optimismo maduran, si la sociedad, acedada hasta en sus capas más bajas por semejante cultura, se estremece poco a poco bajo hervores y deseos exuberantes, si la creencia en la felicidad terrenal de todos, si la creencia en la posibilidad de tal cultura universal del saber se trueca poco a poco en la amenazadora exigencia de semejante felicidad terrenal alejandrina, en el conjuro de un deus ex machina euripideo! Nótese esto: la cultura alejandrina necesita un estamento de esclavos para tener una existencia duradera: pero, en su consideración optimista de la existencia, niega la necesidad de tal estamento, y por ello, cuando se ha gastado el efecto de sus bellas palabras seductoras y tranquilizadoras acerca de la "dignidad del ser humano" y de la "dignidad del trabajo», se encamina poco a poco hacia una aniquilación horripilante. No hay nada más terrible que un estamento bárbaro de esclavos que haya aprendido a considerar su existencia como una injusticia y que se disponga a tomar venganza no solo para sí, sino para todas las generaciones. Frente a tales amenazadoras tempestades, quién se atreverá a apelar con ánimo seguro a nuestras pálidas y fatigadas religiones, las cuales han degenerado en sus fundamentos hasta convertirse en religiones doctas: de tal modo que el mito, presupuesto necesario de toda religión, está ya en todas partes tullido, y hasta en este campo ha conseguido imponerse aquel espíritu optimista del que acabamos de decir que es el germen de aniquilamiento de nuestra sociedad (§18, 146-147).

Efectivamente, a partir de la adopción como válidos por parte de las capas sociales bajas de los pará- metros normativos con los que se define a sí misma la cultura moderna, surge la exigencia de que lo que 
promete la ideología de la sociedad liberal burguesa (igualdad de derechos, bienestar material, formación general) se realice efectivamente. Esta exigencia es calificada por Nietzsche como "exigencia amenazadora y espantosa, que, teniendo en cuenta los movimientos socialistas del presente, nosotros no podemos dejar de oír. El «hombre bueno primitivo» quiere sus derechos", comenta Nietzsche citando irónicamente a Rousseau y concluye con sorna: "iqué perspectivas paradisíacas!" (\$19, 154). Esta situación permite a Nietzsche hablar de una "quiebra" de la cultura moderna y la define a partir del hecho de que "el hombre teórico se asusta de sus consecuencias" $(\$ 18,149)$. La quiebra de la cultura moderna consiste en que los fundamentos ideológicos de esta cultura (la idea de que el progreso científico, tecnológico y social puede ir estableciendo, sin una modificación del carácter clasista de la sociedad burguesa, condiciones materiales de vida dignas para todos, una extensión universal de la formación y una eliminación paulatina del sufrimiento) generan expectativas sociales que acaban deslegitimando la estructura social asimétrica y jerárquica, basada en la esclavización de la fuerza de trabajo dedicada a la reproducción material de la sociedad, que pone las condiciones que hacen posible la cultura alejandrina y en realidad toda cultura elevada en cuanto tal (pues para Nietzsche toda cultura elevada exige la existencia de un estamento de esclavos que efectúe la reproducción material de la sociedad y descargue de tales pesados menesteres a la élite dedicada a la producción cultural). ${ }^{11}$ Con ello, los fundamentos ideológicos de la sociedad moderna, aquellos parámetros normativos con los que se identifica a sí misma, quedan puestos en cuestión ante sus mismos representantes: la idea de progreso, de bienestar material general, de formación universal, de dignidad del ser humano y de dignidad del trabajo, de eliminación del sufrimiento, se tornan problemáticas para los mismos grupos dirigentes de la sociedad moderna. ${ }^{12}$ Según el clarividente análisis del primer Nietzsche, esto va a provocar un paulatino distanciamiento de las élites respecto a tales principios, va a generar en ellas una actitud cínica respecto a los parámetros normativos moderno-ilustrados, de los que se va a servir para justificar su posición de poder pero va a negar sistemáticamente, sin mostrar conciencia de contradicción alguna, en la práctica. Nietzsche logra tematizar así el prototipo de la deriva de la actitud de la burguesía en el poder respecto a los valores e ideales que legitiman como racional a la sociedad burguesa, es decir, hacia una actitud instrumental o cínica que se radicaliza en los periodos de crisis social, tal como resulta perceptible en nuestro presente.

En este sentido, Nietzsche adopta el pathos trágico como base 
para rechazar las promesas institucionalizadas en la sociedad moderna y que forman parte de su ideología legitimatoria. Es decir, rechaza la ideología liberal burguesa por la promesa que contiene (promesa que para la tradición de pensamiento marxista constituye el contenido de verdad de la ideología), ${ }^{13}$ la cual -este es el peligro- puede ejercer una influencia perjudicial sobre los que sufren la sociedad jerarquizada, provocando el surgimiento de expectativas incompatibles con la reproducción de la sociedad jerarquizada y desigualitaria vigente. En estas expectativas percibe Nietzsche la amenaza más grave para el tipo de sociedad base de toda forma de cultura, también de la trágica, es decir una sociedad en la que se da una división del trabajo entre la mayoría, que se ocupa de la reproducción material de la sociedad, y una minoría encargada de la producción artístico-cultural y en la que los primeros serían los medios e instrumentos de los segundos. En relación a esto, Nietzsche defiende explícitamente una concepción trágica del Estado y de la sociedad (ver el texto póstumo de Nietzsche de 1872 "El Estado griego"). ${ }^{14}$ El Estado trágico, en tanto que instalado en la constatación de que el mal es inherente a la vida y de que la redención de lo Uno primordial se lleva a cabo en la forja de una cultura artística trágica que exige la existencia de un estamento de esclavos, se ha desembarazado por fin de la ideología liberal burguesa con sus peligrosas prome- sas, cuyo cumplimiento por parte de la población esclavizada significaría la subversión de tal orden social, y ha conseguido imponer sobre las masas un horizonte de expectativas sociales cercenado compatible con esa jerarquización social que hace posible la elaboración de una cultura elevada y su fruto más excelso, el genio artístico.

En su obra madura este reproche a la cultura y a la sociedad modernas de que generan expectativas que amenazan volverse contra la estructura misma que las sostiene sigue jugando un papel central. Así, respecto a "La cuestión obrera", el último Nietzsche sostiene que a pesar de que la reproducción de la estructura social asimétrica exige la existencia de "esclavos", el discurso político-moral moderno-ilustrado ha impulsado la otorgación al obrero de una serie de derechos (poder servir como soldado, derecho de asociación, derecho al voto) que han impedido que se consolidara como un estamento meramente servil que no pone en cuestión su situación. Aquí constata Nietzsche la misma contradicción que respecto a la cultura socrático-alejandrina: se quiere una cosa (la reproducción de una estructura asimétrica que condena a la mayoría a la esclavitud), pero se hace lo contrario (se educa a los esclavos como ciudadanos formalmente iguales a los señores, es decir, como sujetos capaces de percibir su situación de esclavitud como injusta): 
Yo no alcanzo a ver qué es lo que se quiere hacer con el obrero europeo, después de haber hecho de él una cuestión. Ese obrero se encuentra demasiado bien para no hacer cada vez más preguntas, para no preguntar de manera cada vez más inmodesta. En última instancia tiene a su favor el gran número. Ha desaparecido completamente la esperanza de que una especie de hombre modesta y satisfecha de sí, un tipo de chino forme aquí un estamento: y esto habría tenido una razón, eso habría sido realmente una necesidad. ¿Qué se ha hecho? - Todo, para aniquilar en germen incluso el presupuesto de eso, - han sido destruidos de raíz, con la irreflexión más irresponsable, los instintos en virtud de los cuales un obrero deviene posible como estamento, deviene posible él mismo. Se le ha hecho al obrero apto para el servicio militar, se le ha dado el derecho de asociación, el derecho político al voto: ¿cómo puede extrañar que el obrero sienta ya hoy su existencia como una situación calamitosa (dicho moralmente, como una injusticia -)? ¿Pero qué es lo que se quiere?, volvemos a preguntar. Si se quiere una finalidad, hay que querer también los medios: si se quiere esclavos, se es un necio si se los educa para señores. ${ }^{15}$

La actitud que Nietzsche defiende es por tanto la honestidad, es ser consecuentes con lo que se quiere, no recurrir a falsos adornos o a encubrimientos ideológicos: si se quiere esclavos, hay que educarlos para esclavos, es decir, ubicarlos en un horizonte de expectativas lo suficientemente amputado y empobrecido como para posibilitar la reproducción fluida de la sociedad estamental. También en el periodo maduro de Nietzsche se percibe claramente cómo el pathos trágico nietzscheano sirve como base para lo que podríamos llamar una crítica de la crítica de las asimetrías e injusticias sociales. El texto posiblemente más claro al respecto se encuentra en Más allá del bien y del mal. Se trata de un conocido parágrafo de la sección novena del libro, titulada "¿Qué es aristocrático?" y que vamos a citar por completo:

Abstenerse mutuamente de la ofensa, de la violencia, de la explotación: equiparar la voluntad de uno a la voluntad del otro: en un cierto sentido grosero esto puede llegar a ser una buena costumbre entre los individuos, cuando están dadas las condiciones para ello (a saber, la semejanza efec- 
tiva entre sus cantidades de fuerza y entre sus criterios de valor, y su homogeneidad dentro de un solo cuerpo). Mas tan pronto como se quiera extender ese principio e incluso considerarlo, en lo posible, como principio fundamental de la sociedad, tal principio se mostraría enseguida como lo que es: como voluntad de negación de la vida, como principio de disolución y de decadencia. Aquí resulta necesario pensar a fondo y con radicalidad y defenderse contra toda debilidad sentimental: la vida misma es esencialmente apropiación, ofensa, avasallamiento de lo que es extraño y más débil, opresión, dureza, imposición de formas propias, anexión y al menos, en el caso más suave, explotación, ¿mas para qué emplear siempre esas palabras precisamente, a las cuales se les ha impreso desde antiguo una intención calumniosa? También aquel cuerpo dentro del cual, como hemos supuesto antes, trátanse los individuos como iguales - esto sucede en toda aristocracia sana - debe realizar, al enfrentarse a otros cuerpos, todo eso de lo cual se abstienen entre sí los individuos que están dentro de él, en el caso de que sea un cuerpo vivo y no un cuerpo moribundo: tendrá que ser la encarnada voluntad de poder, querrá crecer, extenderse, atraer a sí, obtener preponderancia, - no partiendo de una moralidad o inmoralidad cualquiera, sino porque vive, y porque la vida es cabalmente voluntad de poder. En ningún otro punto, sin embargo, se resiste más que aquí a ser enseñada la consciencia común de los europeos: hoy se fantasea en todas partes, incluso bajo disfraces científicos, con estados venideros de la sociedad en los cuales desaparecerá "el carácter explotador»: - a mis oídos esto suena como si alguien prometiese inventar una vida que se abstuviese de todas las funciones orgánicas. La «explotación» no forma parte de una sociedad corrompida o imperfecta y primitiva: forma parte de la esencia de lo vivo, como función orgánica fundamental, es una consecuencia de la auténtica voluntad de poder, la cual es cabalmente la voluntad propia de la vida. - Suponiendo que como teoría esto sea una innovación, - como realidad es el hecho primordial de toda historia [das Ur-Faktum aller Geschichte]: iseamos, pues, honestos con nosotros mismos hasta este punto! ${ }^{16}$

La argumentación de Nietzsche parte de la constatación de cuál es la esencia de la vida, de la esencia inmodificable de la vida, 
a saber, su ser voluntad de poder, lo cual implica que "la vida misma es esencialmente apropiación, ofensa, avasallamiento de lo que es extraño y más débil, opresión, dureza, imposición de formas propias, anexión y al menos, en el caso más suave, explotación". Lo significativo de la argumentación de Nietzsche es el salto que efectúa entre los ámbitos de la vida (lo que la vida esencialmente es) y la sociedad. Para Nietzsche tiene que haber una concordancia, una correspondencia, entre lo que la vida esencialmente es y la estructura social. Si la vida es esencialmente explotación, entonces resulta claro que la instauración como "principio fundamental de la sociedad" de la abstención mutua de ofensa, violencia y explotación es efectivamente un acto de "negación de la vida", es decir, de nihilismo y, como tal, un rasgo de debilidad, de enfermedad y agotamiento. Pero, como hemos visto, el pathos trágico, afirmativo, efectúa justamente el acto opuesto: la afirmación incondicional de la vida a pesar de la inherencia a ella de lo que la perspectiva moral judeo-cristiana califica de aspectos terribles. El pathos trágico afirma pues la vida con su componente inherente de sufrimiento. Desde tal pathos Nietzsche puede criticar el planteamiento de Marx como una mera fantasía, aunque con ropaje científico, sobre una sociedad futura sin explotación. Se trata de una pura fantasía, pues no tiene en cuenta lo que el pesimista de la fortaleza sabe: que la explotación es inherente a la vida y, en consecuencia, debe ser también la base de la formación social, lo cual no supone ninguna objeción respecto a la vida ni respecto a una sociedad estructurada en concordancia con la misma, pues todo lo que forma parte de la esencia de la vida, también la explotación, está plenamente justificado más allá del bien y del mal.

Esta afirmación y justificación de la vida, tal como efectiva y constitutivamente es, es realizada por lo trágico en la particular interpretación que Nietzsche realiza de él. Como ha mostrado P. Szondi, en la tradición literaria y filosófica en lengua alemana, durante los siglos XVIII y XIX, han coexistido una diversidad de concepciones de lo trágico, siendo una de ellas (rastreable en la obra de Schelling, Goethe, Hegel o Kierkegaard) la que afirma que lo trágico se da fundamentalmente como conflicto irresoluble e insuperable entre instancias contrapuestas que mantienen cada una su derecho de ser frente a la otra (de ahí que en Hegel el modelo de lo trágico lo diera Antígona y no Edipo Rey). Lo trágico solo se daría, según esta concepción, cuando el conflicto entre las instancias enfrentadas es mantenido con lucidez y no rehuído a través de una disolución del conflicto por ejemplo a partir de la afirmación de uno de los dos polos y la renuncia o rechazo del otro. ${ }^{17}$ Esta concepción de lo trágico da la clave de la idea de absurdo de A. 
Camus. Según este autor, lo absurdo surge de la confrontación entre el deseo de sentido y de claridad inherente al ser humano y "el silencio irrazonable del mundo". ${ }^{18}$ Si se destruye uno de estos dos términos, es decir, si se renuncia a la exigencia de sentido o se afirma el mundo en su irracionalidad constitutiva, lo absurdo se disuelve. Para Camus, lo absurdo, en cuanto confrontación entre el ansia humana de sentido y la frustración de esta necesidad por parte de un universo que no conoce la justicia ni la piedad, debe ser mantenido con plena lucidez en una actitud de permanente rebeldía contra un mundo que niega las expectativas humanas más esenciales. Es esta rebelión fundamental (podríamos decir: existencial) contra lo que meramente es, y que es la base del posicionamiento político de Camus contra la injusticia social, ${ }^{19}$ lo que la peculiar versión nietzscheana del pathos trágico hace desaparecer y posibilita que pueda servir a Nietzsche de base para cuestionar los esfuerzos de transformación de la facticidad social asimétrica en pos de la justicia

\section{Notas}

1 Este escrito ha sido realizado en el marco de las actividades del proyecto de investigación "Las bases filosóficonormativas de la crítica en un marco global y plural" (FFI2010-15065), financiado por el Ministerio de Economía y Competitividad.
Podríamos acabar sosteniendo que Nietzsche no fue quizá enteramente desleal a la tarea de la filosofía propugnada por él mismo en la cuarta Consideración intempestiva (1876): "Me parece que la cuestión más importante de toda filosofía es hasta qué punto tienen las cosas una articulación y una figura inalterables: para luego, cuando se haya resuelto esta cuestión, acometer con la valentía más despiadada el mejoramiento de esa parte del mundo reconocida como modificable". ${ }^{20}$ Pero resulta palpable, en primer lugar, que en su concepción de la vida como explotación introdujo factores que poseen un carácter propiamente humano, social. ${ }^{21} \mathrm{Y}$, en segundo lugar, que de su afirmación trágica de la esencia de la vida como explotación derivó de manera ilegítima prescripciones de un color político muy determinado sobre la estructura social, como si lo que el sabio trágico nos dice acerca de lo que la vida esencialmente es (la physis) tuviera que ser la base normativa para lo que la sociedad (el nomos) debe ser, lo cual constituye a todas luces una versión muy poco elaborada de la falacia naturalista.

2 F. Nietzsche, De la utilidad y los inconvenientes de la historia para la vida, en Antología, Barcelona, Península, 1988, p. 56. Sobre la intempestividad del primer Nietzsche, véase J. Quesada, Un pensamiento intempestivo. Ontología, estética y politica en F. Nietzsche, Barcelona, Anthropos, 1988. 
3 Ver M. Barrios, Voluntad de lo trágico. El concepto nietsscheano de voluntad a partir de "El nacimiento de la tragedia", Madrid, Biblioteca Nueva, 2002 y G. Cano, Nietzsche y la critica de la modernidad, Madrid, Biblioteca Nueva, 2001.

4 F. Nietzsche, El nacimiento de la tragedia, Madrid, Alianza, 1973. Los números entre paréntesis remiten a los parágrafos del libro y a las páginas de esta edición.

5 Sobre la caracterización nietzscheana del arte como afirmativo de la inmanencia, ver L. E. de Santiago Guervós, Arte y poder. Aproximación a la estética de Nietzsche, Madrid, Trotta, 2004. Me he ocupado de este asunto en mi trabajo "Estética e inmanencia en el pensamiento de Nietzsche", en Philosophica. Revista del Instituto de Filosofia de la Pontificia Universidad Católica de Valparaíso, vol. 27, 2004, pp. 247-265.

6 Ver sobre esto el ya clásico estudio de J. D. Arras, "Art, Truth and Aesthetics in Nietsche's Philosophy of Power", en Nietzsche-Studien, vol. 9, 1980, pp. 239-259.

7 En el primer Nietzsche se muestra ese sentimiento de malestar en la modernidad que podemos rastrear en la Alemania en proceso de rápida modernización de la segunda mitad del siglo XIX y que se manifiesta de manera ejemplar en las teorías sociales posteriores de autores como G. Simmel, F. Tönnies y M. Weber. Lo característico del malestar en la modernidad del primer Nietzsche va a ser la búsqueda del remedio para el mal que es la modernidad ilustrada en la antigüedad griega, en concreto en su arte y en su política, tal como veremos a continuación.

8 Posteriormente, en sus Consideraciones intempestivas, Nietzsche se distanciará del explícito nacionalismo político belicista de la posición defendida en su primera obra. En sus Consideraciones intempestivas, el problema se va a formular en los términos del peligro al que la cultura alemana (es decir, Nietzsche no trasciende todavía el marco nacional alemán a la hora de definir su problemática) está sometida por la amenaza representada por el nacionalismo político triunfante tras la victoria en la guerra sobre Francia.

9 Ver A. Schopenhauer, El mundo como voluntad y representación, Madrid, Trotta, 2009, 2 vols. Una clarificadora visión de conjunto del pensamiento de este autor la aporta A. Philonenko, Schopenhauer. Una filosofía de la tragedia, Barcelona, Anthropos, 1989.

10 Sobre esta temática ver H. Röttges, Nietzsche und die Dialektik der Aufklärung, Berlín/Nueva York, Walter de Gruyter, 1972, pp. 211-221.

11 Resulta pertinente realizar un breve contraste con un pensador que ha sido ubicado a menudo en la proximidad de Nietzsche, a saber, Walter Benjamin. En sus tesis sobre el concepto de historia sostuvo que el materialista histórico no puede sino adoptar la actitud de "un espectador distanciado" respecto a los llamados "bienes de cultura", pues "los bienes culturales que abarca con la mirada, tienen todos y cada uno un origen que no podrá considerar sin horror. Deben su existencia no solo al esfuerzo de los grandes genios que los han creado, sino también a la servidumbre anónima de sus contemporáneos. Jamás se da un documento de cultura sin que lo sea a la vez de la barbarie." W. Benjamin, Discursos interrumpidos I, Madrid, Taurus, 1987, pp. 181-182. Como Nietzsche, Benjamin constata que la producción de alta cultura exige la esclavización de la mayoría al servicio de los genios productores de cultura. Pero la valoración que realiza de ello es inversa a la de Nietzsche. Si este piensa que la liberación de los esclavos, en 
cuanto que aniquilación de la condición de existencia de la alta cultura, conduce a la barbarie, para Benjamin es la existencia misma de la alta cultura sostenida en una división del trabajo que condena a la mayoría al estatuto de "servidumbre anónima" lo que debe ser caracterizado de auténtica barbarie.

12 También Marx diagnosticó un proceso análogo en la sociedad burguesa de mitad del siglo XIX, aunque, claro está, tal diagnóstico está realizado desde unos parámetros políticos contrapuestos a los de Nietzsche: "La burguesía tenía la conciencia exacta de que todas las armas forjadas por ella contra el feudalismo se volvían contra ella misma, de que todos los medios de cultura alumbrados por ella se rebelaban contra su propia civilización, de que todas las llamadas libertades civiles y los organismos de progreso atacaban y amenazaban al mismo tiempo, en la base social y en la cúspide política, a su dominación de clase y, por tanto, se habían convertido en "socialistas»". K. Marx, El 18 Brumario de Luis Bonaparte, Madrid, Espasa Calpe, 1980, p. 290.

13 Cf. Th. W. Adorno, "Contribución a la doctrina de las ideologías", en id., Escritos sociológicos I, Madrid, Akal, 2004, pp. 427-446. Si para la crítica de la ideología de matriz marxista había que denunciar la forma ideológica de los valores y conceptos normativos con los que la sociedad burguesa se identifica a sí misma (como ya realizados) con objeto de realizar efectivamente su contenido de verdad, la promesa que contienen, Nietzsche quiere renunciar por completo a los valores y conceptos normativos modernos precisamente a causa de la promesa que contienen, cuya realización supone el mayor de los peligros.
14 Ver F. Nietzsche, Obras completas, Madrid, Tecnos, 2011, vol. I. Sobre este tema, ver el excelente estudio de J. E. Esteban Enguita, El joven Nietzsche. Politica y tragedia, Madrid, Biblioteca Nueva, 2004. También he tratado este tema en mi trabajo Hybris y sujeto. La ética-estética del joven Nietzsche, Morelia (México), Jitanjáfora Editorial, 2007, pp. 88-112.

15 F. Nietzsche, Crepuisculo de los idolos, Madrid, Alianza, 1973, pp. 117-118.

16 F. Nietzsche, Más allá del bien y del mal, Madrid, Alianza, 1997, \$259, pp. 324325 (cf. F. Nietzsche, Werke. Kritische Studienausgabe, Berlín/Nueva York, Walter de Gruyter/Dtv, 1988, vol. 5, pp. 207-208).

17 Ver P. Szondi, Teoría del drama moderno (1880-1950). Tentativa sobre lo trágico, Madrid, Editorial Dykinson, 2011.

18 A. Camus, El mito de sísifo, Madrid, Alianza, 1988, p. 44.

19 Ver A. Camus, El hombre rebelde, Madrid, Alianza, 1987.

20 F. Nietzsche, Obras Completas, ed. cit., vol. I, p. 816 (traducción modificada, of. F. Nietzsche, Werke. Kritische Studienausgabe, ed. cit., vol. 1, p. 445).

21 En otro lugar sostuve que es muy posible que Nietzsche introdujera en el carácter inalterable de las cosas, en la esencia de la vida y del mundo, factores que poseen, según su irónica expresión, un carácter bumano, demasiado bumano. Ver mi trabajo "Los frágiles cimientos del presente. La genealogía nietzscheana y la verdad de la historia", en Estudios Nietzsche, no 3, 2003, pp. 141-161. 